Special issue of the 2nd International Conference on Computational and Experimental Science and Engineering (ICCESEN 2015)

\title{
Influence of Growth Conditions of Hydrogenated Amorphous Silicon Carbide on Optical Properties of the Interfacial Layer in SiC-Based Photodevice
}

\author{
S. $\mathrm{KACI}^{a, *}$, A. Keffous ${ }^{a}$, I. Bozetine ${ }^{a}, \mathrm{M}$. Trari ${ }^{b}$ And O. Fellahi ${ }^{a}$ \\ ${ }^{a}$ Research Center on Semiconductor Technology for Energetic, 2 Bd Frantz Fanon, PB 140, 7M Algiers, Algeria \\ ${ }^{b}$ University of Science and Technology Houari Boumediene, PB 32, ElAlia, Bab Ezzouar, Algiers, Algeria
}

The attention has been focused on the optical properties of structures of the form $\mathrm{Au} / \mathrm{MS} / \mathrm{a}$ $\mathrm{Si}_{1-x} \mathrm{C}_{x}: \mathrm{H} / \mathrm{Si}(100) / \mathrm{Al}$ as a function of the deposition temperature of the a-Si ${ }_{1} \mathrm{C}_{x}: \mathrm{H}$ films. The amorphous $\mathrm{SiC}: \mathrm{H}$ films were obtained for different temperatures ranging from $150{ }^{\circ} \mathrm{C}$ up to $500^{\circ} \mathrm{C}$. By photoluminescence, blue emission from all the structures was observed at room temperature and a high emission was obtained for sample whose amorphous film was deposited at $500{ }^{\circ} \mathrm{C}$. The spectral response of $\mathrm{Au} / \mathrm{MS} / \mathrm{a}-\mathrm{Si}_{1-x} \mathrm{C}_{x}: \mathrm{H} / \mathrm{Si}(100) / \mathrm{Al}$ structures with a-Si ${ }_{1-x} \mathrm{C}_{x}: \mathrm{H}$ film deposited at $250^{\circ} \mathrm{C}$, exhibits a maximum value at $\lambda=950 \mathrm{~nm}$ while for structure with a-Si ${ }_{1-x} \mathrm{C}_{x}: \mathrm{H}$ film obtained at $150^{\circ} \mathrm{C}$, a maximum value of $\lambda$ was observed at $400 \mathrm{~nm}$.

DOI: 10.12693/APhysPolA.130.463

PACS/topics: 78.68. $+\mathrm{m}, 78.66 .-\mathrm{w}, 78.67 . \mathrm{Bf}, 78.55 .-\mathrm{m}$

\section{Introduction}

The presence of an interfacial layer at the metalsemiconductor structures plays an important role in the determination of the characteristic parameters of the devices $[1,2]$. Amorphous silicon carbide has been extensively studied over this decade mainly in the Schottky diode. White-green, yellowish and red light electroluminescence were observed at room temperature in a-SiC $/ \mathrm{n}$ a-SiC diode $[3,4]$. In this work, $\mathrm{Au}-\mathrm{SiC}$ interface has been modified by a thin layer of metal sulfide, MS (PbS specifically). Synthesis of luminescent nanocrystalline MS ( $\mathrm{M}=\mathrm{Pb}, \mathrm{Cd})$ thin films were done in order to introduce them as interfacial layer [5]. Lead sulfide $(\mathrm{PbS})$ is an important member of the chalcogenides which offers large tenability. Its narrow band gap can be varied in a wide range, up to $2.3 \mathrm{eV}$, from the bulk value of $0.41 \mathrm{eV}$, by changing the mean cluster size of the nanoclusters [6]. It permits size quantization effects of size confinement [7]. This semiconductor is an important functional material and has been used in several applications such as IR detector [8], solar absorber [9], $\mathrm{Pb}^{2+}$ ion-selective sensors [10], $\mathrm{NO}_{2}, \mathrm{NH}_{3}$ and $\mathrm{H}_{2}$ gas sensors [11-13]. In order to study the possibility to develop heterojunctions which could be suitable for applications in optoelectronic devices such as light emitting diodes, heterojunctions based on nc-MS/a-SiC:H (with $\mathrm{M}=\mathrm{Pb}$ ) were investigated. Optical properties were investigated using optical response and photoluminescence.

\footnotetext{
*corresponding author; e-mail: k_samira05@yahoo.fr
}

\section{Experimental procedure}

Nanostructured thin films of metal sulfide (MS) $(\mathrm{M}=\mathrm{Pb})$ have been chemically deposited on small chips of $\left(10 \times 5 \mathrm{~mm}^{2}\right)$ a- $\mathrm{Si}_{1-x} \mathrm{C}_{x}: \mathrm{H} / \mathrm{pSi}(100)$ substrates. a$\mathrm{Si}_{1-x} \mathrm{C}_{x}: \mathrm{H}$ films were prepared in a magnetron dc sputtering system. The a-Si ${ }_{1-x} \mathrm{C}_{x}: \mathrm{H}$ films of $0.543,0.72$, and $0.76 \mu \mathrm{m}$ thicknesses were deposited on single crystalline silicon (100) wafers and temperature deposition were 150,250 , and $500{ }^{\circ} \mathrm{C}$, respectively. Optical transmittance measurements were carried out using an UV-VISNIR spectrophotometer (CARY 500 Version 8, 01) in the range of $250-2500 \mathrm{~nm}$ in order to calculate the $\mathrm{SiC}$ thin films thicknesses by using interference fringes method. Preparation of the MS deposition bath: $\mathrm{M}\left(\mathrm{CH}_{3} \mathrm{COO}\right)_{2}$, trihydrate (with $\mathrm{M}=\mathrm{Pb}$ ) and $1 \%$ of polyethylene glycol 300 (PEG300) were dissolved in deionized water $(100 \mathrm{ml})$, with $\mathrm{NaOH}$ and of thiourea. The deposition temperature of MS was $60^{\circ} \mathrm{C}$. Spectral response measurements were carried out by using a tungsten filament lamp with incident power $170 \mathrm{~W}$ with a JOBIN YVON monochromatic in the range $350-1100 \mathrm{~nm}$ wavelength. Photoluminescence spectra of samples excited with wavelength of $325 \mathrm{~nm}$ were measured using a PERKIN-ELMER LS 50B luminescence spectrometer.

\section{Results and discussion}

3.1. Spectral response

Nanostructured thin films of lead sulfide $(\mathrm{PbS})$ have been chemically deposited on $\mathrm{a}_{-} \mathrm{Si}_{1-x} \mathrm{C}_{x}: \mathrm{H} / p$ $\mathrm{Si}(100)$ substrates whose amorphous silicon carbide thin films were deposited at different temperatures. The fabricated samples, $\mathrm{A}: \mathrm{Au} / \mathrm{PbS} / \mathrm{a}-\mathrm{Si}_{1-x} \mathrm{C}_{x}: \mathrm{H}(d=$ $0.72 \mu \mathrm{m}) / p-\mathrm{Si}(100) / \mathrm{Al}$, and $\mathrm{B}: \mathrm{Au} / \mathrm{PbS} / \mathrm{a}_{-}-\mathrm{Si}_{1-x} \mathrm{C}_{x}: \mathrm{H}$ 
$(d=0.76 \mu \mathrm{m}) / p$-Si $(100) / \mathrm{Al}$ and the reference $\mathrm{Au} / \mathrm{a}$ $\mathrm{Si}_{1-x} \mathrm{C}_{x}: \mathrm{H} / p$-Si(100)/Al, have been investigated. From Fig. 1b, the quantum efficiency, for sample B, increases with the increase of wavelength, reaching a maximum at $\lambda=950 \mathrm{~nm}$ and then decreases for values of $\lambda \geq$ $1000 \mathrm{~nm}$. Contrary to sample B, sample A exhibits the opposite phenomena. The quantum efficiency reached a maximum at short wavelengths, $\lambda=450 \mathrm{~nm}$ and then decreases for higher wavelengths. The thickness of the amorphous thin film in sample $\mathrm{B}$ is $d=0.76 \mu \mathrm{m}$ and in sample $\mathrm{A}$, it was $d=0.72 \mu \mathrm{m}$. The forms of the two spectral responses of $\mathrm{Au} / \mathrm{MS} / \mathrm{a}-\mathrm{Si}_{1-x} \mathrm{C}_{x}: \mathrm{H} / p$ $\mathrm{Si}(100) / \mathrm{Al}$ structures (samples $\mathrm{A}$ and $\mathrm{B}$ ) indicates that the a-Si $i_{1-x} \mathrm{C}_{x}: \mathrm{H}$ films morphology varied from sample to other. Consequently, illuminating the different structures of $\mathrm{Au} / \mathrm{MS} / \mathrm{a}-\mathrm{Si}_{1-x} \mathrm{C}_{x}: \mathrm{H} / p$-Si(100)/ $\mathrm{Al}$ from the side of the $\mathrm{Au} / \mathrm{MS} / \mathrm{a}-\mathrm{Si}_{1-x} \mathrm{C}_{x}: \mathrm{H}$ junction, could present different responses as the amorphous films change.

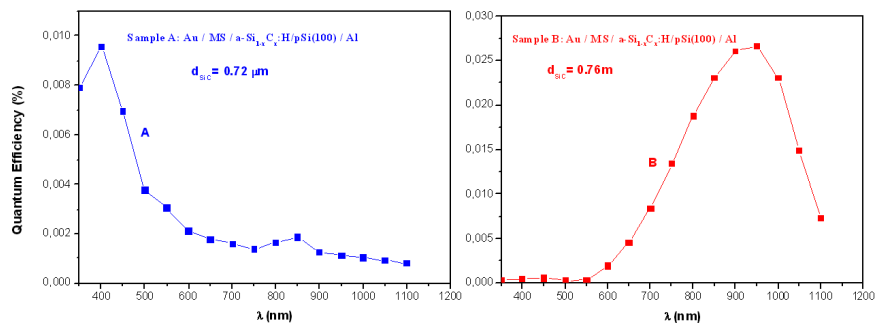

Fig. 1. Quantum efficiency of the $\mathrm{Au} / \mathrm{MS} / \mathrm{a}-\mathrm{SiC}: \mathrm{H} / p$ $\mathrm{Si}(100) / \mathrm{Al}$ structures as function of the wavelength, $\lambda$, for two different temperatures of deposition the a-SiC:H thin films: (a) $150^{\circ} \mathrm{C}$ and (b) $250^{\circ} \mathrm{C}$.

We could suggest that, in sample B, the high energy photons may be absorbed near the surface of the MS, resulting in the generation of electron-hole pairs which cross (electrons and holes moving in opposite directions) the $\mathrm{PbS} / \mathrm{a}-\mathrm{SiC}$ junction and they are collected. As the wavelength, $\lambda$ increases, the main region where absorption of photons takes place is shifted towards the neutral part of a-SiC, and the photogenerated carriers disappear by recombination [14]. By the same way, the high energy photons may be absorbed, in sample A, near the surface of the nanostructured MS films but this time, the generation of electron-hole pairs which cross the MS/a-SiC junction takes place in MS side where the photogenerated carriers disappear by recombination.

\subsection{Photoluminescence}

Figure 2 shows the photoluminescence (PL) emission spectrum of a-Si $\mathrm{Si}_{1-x} \mathrm{C}_{x}: \mathrm{H} / p$ - $\mathrm{Si}(100)$ control sample (without MS) excited at a wavelength of $325 \mathrm{~nm}$. We observed a broad emission band at $438 \mathrm{~nm}$ and a shoulder at $522 \mathrm{~nm}$. The blue emission is the result of the quantum size confinement effect as suggested by $\mathrm{Xu}$ et al. for porous $\mathrm{SiC}[15,16]$, whereas the green luminescence emission centered at $522 \mathrm{~nm}$ has been found to be similar to that observed in bulk $3 \mathrm{C}-\mathrm{SiC}$ and on porous silicon samples [17].

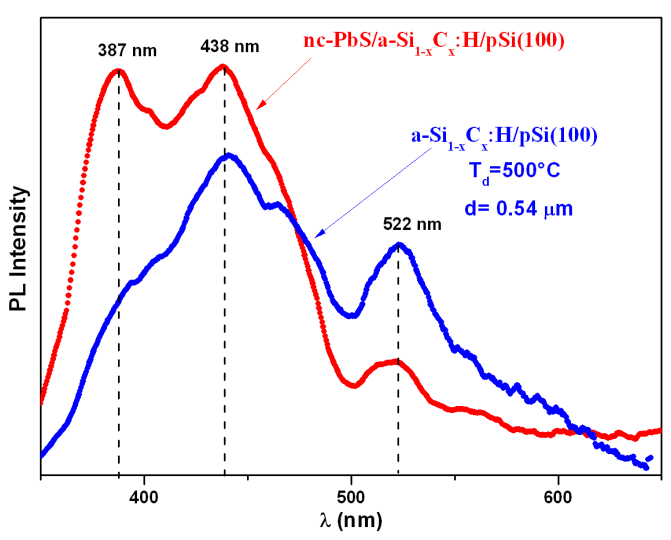

Fig. 2. Room temperature photoluminescence spectra of a- $\mathrm{Si}_{1-x} \mathrm{C}_{x}: \mathrm{H} / p-\mathrm{Si}(100)$ and $\mathrm{MS} / \mathrm{a}-\mathrm{Si}_{1-x} \mathrm{C}_{x}: \mathrm{H} / p$ $\operatorname{Si}(100)(\mathrm{M}=\mathrm{Pb})$.

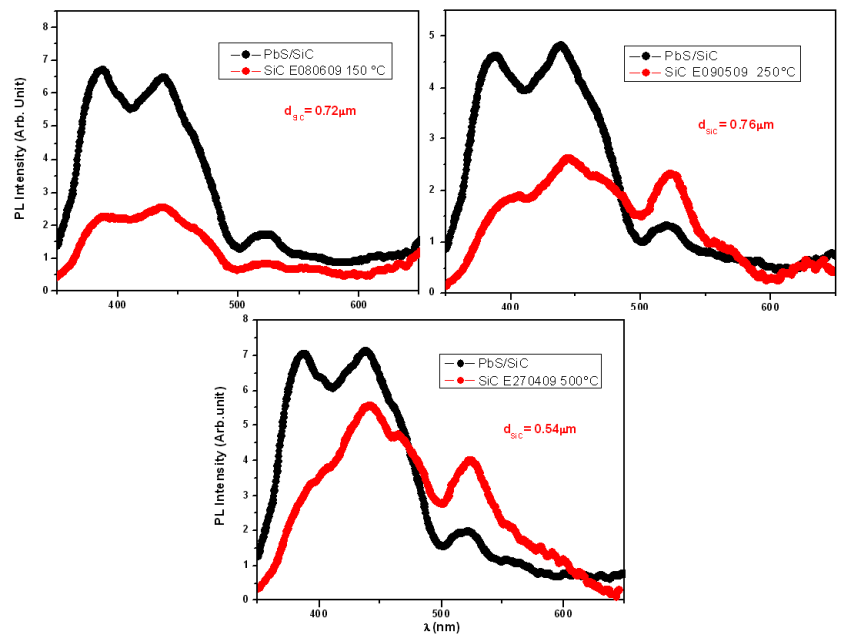

Fig. 3. Room temperature photoluminescence spectra of $\mathrm{MS} / \mathrm{a}-\mathrm{Si}_{1-x} \mathrm{C}_{x}: \mathrm{H} / p-\mathrm{Si}(100)$ with $\mathrm{M}=\mathrm{Pb}$ at different temperatures of the deposited amorphous $\mathrm{SiC}$ thin films.

In Fig. 3, the spectrum shows two strong peaks at $387 \mathrm{~nm}$ and at $438 \mathrm{~nm}$ and a shoulder at $522 \mathrm{~nm}$. As was expected previously, we have found that the peaks were attributed to the emission of $\mathrm{SiC}$ films. Consequently, the peak at $387 \mathrm{~nm}$ is ascribed to the nanostructured MS thin films. This deduction also learns on our previous study [18-20], in which nanocrystalline MS thin film emission was compared to that of MS nanopowder. We have reported that the main emission for the both nature of MS was at $\lambda=387 \mathrm{~nm}$. It shows that as the deposited amorphous film thickness increases, the intensity of the PL of the heterostructure decreases, while its maximum PL peaks position remain unchanged. In addition we note that the deposition temperature of the amorphous film a-Si ${ }_{1-x} \mathrm{C}_{x}: \mathrm{H}$ affects aleatory the intensity of PL of the heterostructures. In other words, there is no correlation in the variation of the PL intensity with the deposition temperature. It could indicate that the 
amorphous films morphology was not the same for all the samples.

\section{Conclusion}

In this study, we demonstrate a UV-blue PL from $\mathrm{MS} / \mathrm{a}-\mathrm{SiC} / p$-Si heterostructures. The properties of the heterojunctions were strongly influenced by the deposition conditions of the amorphous silicon carbide thin films. According to the optical response results, the existence of inhomogeneities in a-Si ${ }_{1-x} \mathrm{C}_{x}: \mathrm{H}$, which lead to highly disordered surface layer, become an evidence and can alter the films morphology of $\mathrm{PbS}$. This fact could affect the reproducibility of data.

\section{Acknowledgments}

This work was completed thanks to the National Funds of Research, DGRSDT/MESRS (Algeria).

\section{References}

[1] H.J. Im, Y. Ding, J.P. Pelz, W.J. Choyke, Phys. Rev. $B$ 64, 075310 (2001).

[2] F. Yakuphanoglu, Synth. Metals 160, 1551 (2010).

[3] F.W. Wise, Acc. Chem. Res. 33, 773 (2000).

[4] D. Kruangam, T. Endo, W.G. Pu, S. Nonomura, H. Okamotoa, Y. Hamakawa, J. Non-Cryst. Solids 77/78, 1429 (1985)

[5] F. Demichelis, F. Giorgis, C.F. Pirri, E. Tresso, Philos. Mag. A 72, 913 (1995).

[6] F.W. Wise, Acc. Chem. Res. 33, 16 (2000).
[7] J.L. Machol, F.W. Wise, R.C. Patel, D.B. Tanner, Phys. Rev. B 48, 2819 (1993).

[8] N.S. Belova, A.A. Rempel, Inorg. Mater. 40, 3 (2004).

[9] I. Pop, C. Nascu, V. Ionescu, E. Indrea, I. Bratu, Thin Solid Films 307, 240 (1997).

[10] P. Gadamne, Y. Yagil, G. Deutscher, J. Appl. Phys. 66, 3019 (1989).

[11] S. Kaci, A. Keffous, S. Hakoum, M. Trari, O. Mansri, H. Menari, Appl. Surf. Sci. 305, 740 (2014).

[12] T. Fu, Sens. Actuat. B 140, 116 (2009).

[13] S. Kaci, A. Keffous, S. Hakoum, O. Mansri, Vacuum 116, 27 (2015).

[14] Y. Gulen, K. Ejderha, C. Nuhoglu, A. Turut, Microelectron. Eng. 88, 179 (2011).

[15] R. Saleh, L. Munis, W. Beyer, Thin Solid Films 426 , 117 (2003).

[16] R. Platz, S. Wagner, C. Hof, A. Shah, S. Wieder, J. Appl. Phys. 84, 3949 (1998).

[17] J. Xu, L. Yang, Y. Rui, J. Mei, X. Zhang, W. Li, Z. Ma, Ling Xu, X. Huang, K. Chen, Solid State Commun. 33, 565 (2005).

[18] S. Kaci, A. Keffous, M. Trari, H. Menari, O. Mansri, B. Mahmoudi, L. Guerbous, Opt. Commun. 283, 3355 (2010).

[19] V. Suendo, G. Patriarche, P.R. Cabarrocas, Opt. Mater. 27, 953 (2005).

[20] S. Kaci, A. Keffous, S. Hakoum, N. Makrani, M. Kechouane, L. Guerbous, Opt. Mater. 35, 1 (2012). 